Disponível em:

http://editora.unoesc.edu.br/index.php/race

Race, Joaçaba, v. 14, n. 3, p. 1035-1062, set./dez. 2015

\title{
A INFLUÊNCIA DO GRAU DE INTANGIBILIDADE NO DESEMPENHO DE EMPRESAS SEDIADAS NOS PAÍSES COM TURBULÊNCIA ECONÔMICA
}

\section{Relationship between performance and intangibility companies based countries with economic turmoil}

Lara Fabiana Dallabona

E-mail:1ara_mestrado@hotmail.com

Doutora em Ciências Contábeis e Administração pela Fundação Universidade Federal de Blumenau; Mestre em Ciências Contábeis pela Fundação Universidade

Federal de Blumenau; Professora da Universidade do Estado de Santa Catarina; Bolsista do Programa do Fundo de Apoio à Manutenção e ao Desenvolvimento da Educação Superior. Endereço para contato: Rua Dr. Getúlio Vargas, 2822, Bela Vista, 89140-000, Ibirama, Santa Catarina, Brasil.

Sady Mazzioni

E-mail: sady@unochapeco.edu.br

Doutor em Ciências Contábeis e Administração pela Fundação Universidade Federal de Blumenau; Mestre em Ciências Contábeis pela Fundação Universidade Federal de Blumenau; Professor da Universidade Comunitária da Região de Chapecó; Bolsista do Programa do Fundo de Apoio à Manutenção e ao Desenvolvimento da Educação Superior;

Endereço: Rua Francisco Norberto Bonher, 55 E, Jardim Itália, 89.802-530, Chapecó, Santa Catarina, Brasil.

\section{Roberto Carlos Klann}

E-mail: rklann@furb.br

Doutor em Ciências Contábeis e Administração pela Fundação Universidade Federal de Blumenau; Mestre em Ciências Contábeis pela Fundação Universidade Federal de Blumenau; Professor do Programa de Pós-Graduação em Ciências

Contábeis da Fundação Universidade Federal de Blumenau.

Artigo recebido em 29 de janeiro de 2014. Aceito em 30 de abril de 2015. 
Resumo

O estudo investiga a influência do grau de intangibilidade sobre o desempenho econômico de empresas sediadas em Portugal, Irlanda, Itália, Grécia e Espanha, pesquisando 604 empresas dos setores econômicos de indústria, utilidades e transportes. A análise dos dados valeu-se do pacote estatístico SPSS ${ }^{\circledR}$, aplicando-se a técnica de regressão linear multivariada. Utilizouse como variáveis dependentes o Retorno sobre Ativos (ROA), o Lucro por Ação (LPA), o Crescimento de Vendas (CV), o Giro do Ativo (GA) e o Retorno sobre o Patrimônio Líquido (ROE); como variáveis independentes, o Grau de Intangibilidade (GI) e as variáveis dummies representando os países e segmentos econômicos. Os resultados demonstram que o GI possui relação positiva e significativa com ROA e negativa e significativa com ROE; em relação às variáveis LPA e CV, não foram constatados resultados estatisticamente significativos; e quanto à variável GA, todas as relações foram positivas, alternando entre significativas - com as empresas de Portugal, Itália, Grécia e Espanha - e não significativas, com empresas da Irlanda e na amostra total. Conclui-se que existe relação significativa entre o grau de intangibilidade e o desempenho econômico das empresas da amostra, corroborando as perspectivas teóricas de que os ativos intangíveis possuem capacidade diferenciada na criação de valor às entidades. Palavras-chave: Ativos intangíveis. Desempenho econômico. Competitividade. Capital intelectual. PIIGS.

\section{The influence of the degree of intangibility in the performance of companies located in countries with economic turmoil}

\section{Abstract}

The study investigates the influence of the degree of intangibility on the economic performance of companies located in Portugal, Ireland, Italy, Greece and Spain, exploring 604 companies from the economic sectors of industry, utilities and transport. Data analysis drew on the SPSS ${ }^{\circ}$ statistical package, applying a multivariate linear regression technique. As dependent variables, we used the return on assets (ROA), Earnings per Share (EPS), Sales Growth (CV), Asset Turnover (GA) and Return on Equity (ROE). As independent variables, the degree of intangibility (GI) and the dummy variables representing countries and economic sectors. The results demonstrate that the GI has a positive and significant relationship with $R O A$ and a negative and significant one with ROE; in relation to LPA and CV variables, no statistically significant results were found, and as the GA variable, all relationships were positive, alternating between significant - with the companies from Portugal, Italy, Greece and Spain - and not significant, with companies from Ireland and the total sample. It is concluded that there is significant relationship between the degree of intangibility and economic performance of companies from the sample, supporting the theoretical perspectives that the intangible assets have differentiated capability in the value creation to the entities. Keywords: Intangible assets. Economic performance. Competitiveness. Intellectual capital. PIIGS. 


\section{INTRODUÇÃO}

O interesse crescente sobre os ativos intangíveis decorre da permanente competição das empresas, acirrada pela globalização do comércio, pela elevada desregulamentação e pelas mudanças tecnológicas constantes que envolvem o ambiente de negócios das empresas e que estabelecem uma persuasão para que as organizações mudem seus modelos operacionais e estratégicos (LEV, 2001). Os estudos de Edvinsson e Malone (1998), Stewart (1998) e Perez e Famá (2006) destacam evidências da representatividade dos ativos intangíveis em relação aos ativos tangíveis das empresas, caracterizando sua relevância e criação de valor para as entidades.

É possível identificar na literatura nacional e internacional diversas nomenclaturas e/ou termos utilizados para os ativos intangíveis, como: intangíveis, ativos intangíveis, ativos intelectuais, ativos invisíveis, propriedade intelectual, capital intelectual, capital incorpóreo, recursos intangíveis, goodwill, entre outros (MARTINS, 1972; EDVINSSON; MALONE, 1998; STEWART, 1998; SVEIBY, 1998; CADDY, 2002; TAN; PLOWMAN; HANCOCK, 2007; HITT; IRELAND; HOSKISSON, 2003). Para o desenvolvimento deste estudo, utilizou-se o termo ativo intangível, por se considerar que reflete melhor o tema investigado, procedimento também adotado nas investigações anteriores de Kayo (2002) e Sriram (2008).

Ativos intangíveis são caracterizados como o conjunto de conhecimentos específicos, práticas e atitudes envolvendo a organização, que com os ativos tangíveis colaboram para a geração de valor. Esses ativos intangíveis não possuem corpo físico e financeiro (KAYO, 2002). O autor utiliza para o cálculo do grau de intangibilidade das empresas o valor de mercado total das ações sobre o patrimônio líquido contábil. É tida como uma medida relativa e considera que quanto maior for o grau de intangibilidade, maior é a participação dos ativos intangíveis na estrutura organizacional (KAYO, 2002).

Nos estudos científicos que foram identificados sobre o termo ativo intangível, identificou-se que há uma preocupação constante em relacionar intangibilidade com o desempenho econômico-financeiro das organizações. Entre os estudos em que se identificou relação positiva entre os ativos intangíveis e o desempenho tem-se: Bontis, Keow e Richardson (2000); Chen, Cheng e Hwang (2005); Perez e Famá (2006); Cohen e Kaimenakis (2007); Tan, Plowman e Hancock (2007); Tovstiga e Tulugurova (2007); Colauto et al. (2009) e Tovstiga e Tulugurova (2009). 
Já nos estudos de Ensslin et al. (2009), Carvalho, Kayo e Martin (2010), Murthy e Mouritsen (2011) e Nascimento et al. (2012), não foi encontrada relação positiva entre os ativos intangíveis e o desempenho econômico-financeiro das organizações analisadas.

Constata-se na literatura que o desempenho e o poder competitivo das organizações geralmente são influenciados pelo ativo intangível das empresas (WANG; CHANG, 2005). Diante de uma economia baseada no conhecimento, o principal fator que impulsiona e cria valor em uma empresa é a intangibilidade. Consequentemente, infere-se que a criação e a acumulação de intangíveis devem ser refletidas no desempenho de uma empresa (WANG; CHANG, 2005).

Com o presente estudo, pretendeu-se investigar a influência dos ativos intangíveis em empresas situadas em Portugal, Irlanda, Itália, Grécia e Espanha. A escolha das empresas recaiu sobre esses países em razão do insatisfatório desempenho econômico experimentado a partir de 2008, quando as economias nacionais foram consideradas vulneráveis, considerando-se o elevado endividamento e o alto déficit público em relação ao Produto Interno Bruto (PIB) dessas nações (PAULA; FERRARI FILHO, 2011). A má performance econômica desses países causou o surgimento do acrónimo PIIGS - sigla formada pelas iniciais de cada país em inglês - cuja forma pejorativa rendeu contestações de autoridades dos países envolvidos.

Diante da escassez de estudos que buscaram investigar a relação dos ativos intangíveis com o desempenho econômico e financeiro de empresas sediadas nos países envolvidos em crise econômica é que se propõe verificar se o aumento na proporção de intangibilidade repercute em melhor desempenho empresarial em ambiente econômico vulnerável. A partir dessas considerações, tem-se a pergunta que norteia o estudo: Qual a influência do grau de intangibilidade sobre as variáveis de desempenho econômico em empresas de capital aberto sediadas em Portugal, Irlanda, Itália, Grécia e Espanha? Com o estudo, objetivou-se investigar a influência do grau de intangibilidade sobre o desempenho econômico de empresas de capital aberto sediadas nesses países, com a finalidade de verificar se a presença mais elevada de ativos intangíveis repercute em maior desempenho.

A escolha pelos países que sediam as empresas investigadas ocorreu em razão de apresentarem características comuns durante a crise econômica iniciada em 2008, como: problema crônico de competitividade externa combinado com desequilíbrios fiscais que variaram de moderado (Espanha) a gravíssimo (Grécia) e regime de crescimento liderado pelo aumento do consumo financiado com endividamento privado e aumento dos preços dos ativos (OREIRO, 2011). 
As crises econômicas provocam a redução de investimentos nas empresas, incluindo o investimento em inovação, cujos retornos são incertos e de longo prazo, conforme constatado na crise financeira de 2008, que reduziu substancialmente a disposição das empresas para investirem em inovação (ARCHIBUGI; FILIPPETTI; FRENZ, 2013). A inovação compõe um grupo importante dos ativos intangíveis, representados pela pesquisa e desenvolvimento, patentes, fórmulas, know how, entre outros (KAYO, 2002).

A motivação para a realização do estudo advém da crescente preocupação e interesse acadêmico e empresarial diante do reflexo que os ativos intangíveis apresentam para o desempenho econômico e financeiro das organizações. Dessa forma, os resultados da pesquisa tornam-se relevantes aos diversos interessados pelo tema. A principal contribuição do estudo é a de fornecer subsídios que concorram para o entendimento da influência dos ativos intangíveis no desempenho de empresas submetidas a um cenário econômico vulnerável.

\section{ATIVOS INTANGÍVEIS}

Os ativos intangíveis ocupam espaço nas empresas que buscam ascendência no mercado em que atuam, como, por exemplo, busca por competitividade e diferenciação das atividades entre concorrentes de setores e atividades diversificadas (GOLDFINGER, 1997; LEV, 2001). Uma das constatações possíveis a partir da literatura é que não há um consenso na definição do que vem a ser um ativo intangível, em que se observa o uso dessa expressão ativo intangível, como sinônimo de determinados recursos intangíveis, ativos intelectuais, ativos invisíveis, capital intelectual, goodwill, entre outros (MARTINS, 1972; EDVINSSON; MALONE, 1998; STEWART, 1998; SVEIBY, 1998; CADDY, 2002; HITT; IRELAND; HOSKISSON, 2008).

A investigação de Kang e Gray (2014) identificou que fatores específicos das empresas (padrão contábil, tipo de indústria, relação valor de mercado/valor contábil) e fatores específicos do país de origem (riscos associados com políticas econômicas e jurídicas) influenciam decisivamente no nível de divulgação das empresas sobre informações dos ativos intangíveis. Arrighetti, Landini e Lasagni (2014) encontraram que o tamanho da empresa, o capital humano e o nível histórico de intensidade em intangíveis aumentam significativamente a probabilidade de investimento em intangíveis, indicando a existência de um processo de acumulação 
de ativos intangíveis. Anteriormente, Axtle-Ortiz (2013) havia encontrado que a região geográfica, o setor econômico e o tamanho da organização são fatores estatisticamente significativos que influenciam a formação dos ativos intangíveis, enquanto Huyghebaert e Luypaert (2010) encontraram que os ativos intangíveis afetam positivamente na decisão de fusões e aquisições.

A investigação de Park et al. (2013) indicou que as multinacionais norteamericanas sofrem destruição de valor quando entram em mercados nas quais as pessoas expressam severo antiamericanismo. No entanto, descobriram que a diversificação geográfica nesses países com elevado antiamericanismo aumenta significativamente o valor da firma se a multinacional tem altos níveis de intangíveis.

Embora muitos tipos de ativos intangíveis possam ser qualificados como ativos estratégicos, são poucos aqueles que atendem às características fundamentais, a exemplo do capital intelectual (HALL, 1992). Ainda que existam diversos conceitos para os ativos intangíveis, formas distintas de cálculo do grau de intangibilidade e o uso de variados indicadores de desempenho, observa-se o interesse de correlacionar tais variáveis.

Ensslin et al. (2009) investigaram a correlação entre os ativos intangíveis e o retorno sobre os investimentos de 45 empresas listadas no índice Bovespa, entre os anos 2005 e 2007. Nos resultados foi encontrada correlação entre a variação do retorno sobre os investimentos e o grau de intangibilidade nas empresas analisadas.

A natureza dos recursos intangíveis e tangíveis sobre o desempenho de cada firma em relação aos seus concorrentes foi analisada no estudo de Carvalho, Kayo e Martin (2010). Os resultados apontaram que a intangibilidade das empresas analisadas não se revelou como vantagem competitiva sustentável, identificando que tais recursos não contribuem para a persistência do desempenho superior das empresas.

O estudo de Murthy e Mouritsen (2011) investigou a relação entre o capital intelectual e o capital financeiro de uma empresa que investe em capital intelectual, a fim de desenvolver o capital financeiro. Os resultados demonstram que as relações entre o capital intelectual e o capital financeiro são difíceis de especificar, porque são complementares e não causais.

Já Nascimento et al. (2012) objetivaram verificar a correlação existente entre o grau de intangibilidade (GI) e os indicadores de desempenho giro do ativo (GA), margem líquida (ML), retorno sobre o ativo (ROA) e retorno sobre o patrimônio líquido (ROE) de oito empresas dos setores de tecnologia da informação e de 20 
empresas de telecomunicações, da Bovespa. Os resultados demonstram que não houve diferenças entre os segmentos que foram analisados.

Considerando que os estudos relatados não identificaram uma possível relação estatística entre os ativos intangíveis das empresas analisadas e o desempenho econômico, desenvolveu-se a hipótese nula que norteia este estudo:

$H_{0}$ - Não há relação entre o grau de intangibilidade e o desempenho econômico de empresas de capital aberto sediadas em Portugal, Irlanda, Itália, Grécia e Espanha.

De forma contrária, foram identificados estudos que relacionaram ativos intangíveis com o desempenho econômico e identificaram uma relação estatisticamente significativa. Bontis, Keow e Richardson (2000) investigaram três elementos do capital intelectual, sendo o capital humano, o capital estrutural e o capital de clientes e suas inter-relações no setor industrial e de serviços, na Malásia. Os resultados demonstram que o capital humano é relevante, independentemente do tipo de indústria analisada e que o desenvolvimento do capital estrutural tem uma relação positiva com o desempenho dos negócios.

Alguns autores destacam que a diferença entre o valor de mercado das ações das empresas e seu valor contábil é consequência da existência de capital intelectual (CI). Para testar essa relação, Sáenz (2005) sugere uma metodologia para estudar a relação entre os indicadores de CI e o valor de mercado das empresas. A amostra contemplou quatro bancos com operações na Espanha que publicaram relatórios sobre o capital intelecutal e o capital humano. Os resultados demonstram relação positiva, porém, não significativa entre os indicadores de capital humano, eficiência dos bancos e retorno financeiro.

No estudo desenvolvido por Perez e Famá (2006), a análise recaiu sobre o impacto da presença dos ativos intangíveis que não foram contabilizados no desempenho das empresas, identificando estatisticamente se os intangíveis podem ser responsáveis por uma criação maior de valor aos acionistas. Os resultados indicaram a existência de desempenho superior nas empresas intangível-intensivas, apresentando maior geração de valor para os acionistas em comparação às empresas tangível-intensivas.

Cohen e Kaimenakis (2007) explicitaram a necessidade de especificar as relações entre as diferentes categorias de ativos intelectuais existentes no contexto de pequenas e médias empresas (PME), para determinar como esses ativos afetam o desempenho financeiro. Os resultados demonstram que certas categorias de capital intelectual contribuem positivamente para o desempenho financeiro das PME. 
Tan, Plowman e Kancock (2007) investigaram a associação entre o capital intelectual e o desempenho financeiro de 150 empresas que estavam listadas na bolsa de Cingapura, entre os anos 2000 e 2002. Os resultados demonstram que o capital intelectual e o desempenho das organizações estão positivamente relacionados, considerando também que o capital intelectual está correlacionado com o desempenho futuro da empresa.

Tovstiga e Tulugurova (2007) pesquisaram o impacto de práticas de capital intelectual no desempenho empresarial de empresas inovadoras localizadas na Região de St. Petersburg, na Rússia. A amostra contempla 20 empresas pertencentes ao setor de alta tecnologia. Os resultados demonstram que o capital intelectual foi o que apresentou maior relevância e importância diante da condução de desempenho competitivo no mercado.

Cabrita e Bontis (2008) analisaram as inter-relações e interações entre os componentes do capital intelectual e o desempenho dos negócios no setor bancário português. O modelo e os testes das hipóteses envolveram 253 participantes de 53 organizações. Os resultados demonstram uma confirmação em relação aos estudos anteriores, fornecendo evidências empíricas de inter-relações entre os componentes do capital intelectual e a influência positiva sobre o desempenho das organizações analisadas.

O impacto competitivo do capital intelectual no desempenho empresarial em pequenas empresas inovadoras foi analisado na investigação de Tovstiga e Tulugurova (2009). A amostra envolve 42 empresas da Rússia, 40 da Alemanha, 22 da Dinamarca e 18 dos Estados Unidos. Os resultados do estudo demonstram que o capital intelectual é considerado o fator mais importante de desempenho competitivo de condução em todas as regiões analisadas pelos autores.

O estudo desenvolvido por Maditinos et al. (2011) objetivou analisar o impacto do capital intelectual sobre o valor das empresas de mercado e desempenho financeiro, contemplando 96 empresas gregas que se encontram listadas na Bolsa de Atenas (ASE) no período de 2006 a 2008. Concluíram que há uma relação estatisticamente significativa entre a eficiência do capital intelectual e o desempenho financeiro das organizações estudadas. Conclui-se que para os negócios das empresas gregas, o desenvolvimento de recursos humanos (intelectuais) se apresentou como um dos mais relevantes fatores de sucesso econômico da região.

O impacto dos ativos intangíveis de conhecimento no desempenho internacional das empresas foi investigado por Denicolai, Zucchella e Strange (2014), por meio da análise de uma amostra de 290 companhias europeias listadas em bolsa. 
Os resultados indicaram que um maior volume de ativos de conhecimento tem um impacto positivo na intensidade externa de vendas, mas é necessário equilibrá-los com ativos complementares para atingir a um maior grau de atuação internacional. Os ativos de conhecimento gerados externamente podem ter um impacto positivo sobre o desempenho internacional, mediados pela posse de ativos de conhecimento gerados internamente.

De acordo com os estudos de Bontis Keow e Richardson (2000), Sáenz (2005); Perez e Famá (2006), Cohen e Kaimenakis (2007), Tan, Plowman e Hancock (2007), Tovstiga e Tulugurova (2007), Cabrita e Bontis (2008), Tovstiga e Tulugurova (2009), Maditinos et al. (2011) e Denicolai, Zucchella e Strange (2014), foi possível identificar relação entre a intangibilidade dos ativos e o desempenho econômico das organizações, fundamentando a apresentação da hipótese alternativa para o desenvolvimento deste estudo:

$\mathrm{H}_{1}$ - Há relação entre o grau de intangibilidade e o desempenho econômico de empresas de capital aberto sediadas em Portugal, Irlanda, Itália, Grécia e Espanha.

\section{ASPECTOS METODOLÓGICOS}

Conforme as características da investigação, a pesquisa pode ser conceituada como descritiva e documental. Quanto à abordagem do problema, o estudo é caracterizado como quantitativo, com aplicação de estatística descritiva e regressão linear múltipla para identificar a influência entre intangibilidade e desempenho econômico-financeiro das empresas analisadas.

A população inicial era formada por 832 empresas de capital aberto sediadas em Portugal, Irlanda, Itália, Grécia e Espanha, que fazem parte de diversos setores econômicos e com seus dados disponibilizados na base de dados da Thomson ${ }^{\circledR}$.

Seguindo procedimento adotado por estudos anteriores, como Perez e Famá (2006), foram excluídas 128 empresas que fazem parte dos segmentos de bancos, seguros e outras empresas financeiras, considerando-se as características específicas dessas empresas. Essas características estão relacionadas à estrutura de propriedade, à composição dos ativos e à possível maior sensibilidade dessas entidades em um ambiente de turbulência econômica.

Também foram excluídas 95 empresas que não disponibilizaram as informações necessárias para a formação das variáveis escolhidas, além de cinco empresas que apresentaram resultados muito discrepantes em relação às médias das 
demais empresas (outliers). Como medida corretiva, os outliers foram retirados da amostra utilizando-se como critério o afastamento entre a média e a observação. Assim, observações com mais ou menos de três desvios padrões foram excluídas e consideradas como observações extraordinárias. Do ponto de vista prático, essas observações atípicas poderiam ter um efeito sensível sobre a análise empírica. Já do ponto de vista substantivo, o número de observações atípicas corresponde a menos de $1 \%$ da amostra final, não tendo representatividade importante (HAIR JÚNIOR et al. 2009).

A amostragem recaiu sobre empresas localizadas em países em situação de turbulência econômica, notoriamente conhecida nos países investigados. O estudo busca a inferência causal entre as variáveis utilizadas (HAIR JUNIOR et al., 2009), ou seja, a relação de dependência entre os indicadores de desempenho e o grau de intangibilidade, os setores econômicos e o país de origem. A partir dessas considerações, a amostra contempla 42 empresas de Portugal, 41 empresas da Irlanda, 199 da Itália, 227 da Grécia e 95 da Espanha, segregadas por tipo de atividade econômica, conforme demonstrado na Tabela 1.

Tabela 1 - Amostra segregada por país e tipo de indústria

\begin{tabular}{crrrr}
\hline País/Empresas & \multicolumn{1}{c}{ Indústria } & Utilidade & Transporte & \multicolumn{2}{c}{ Total } \\
\hline Portugal & 36 & 6 & 0 & 42 \\
Irlanda & 37 & 1 & 3 & 41 \\
Itália & 174 & 21 & 4 & 199 \\
Grécia & 197 & 10 & 20 & 227 \\
Espanha & 84 & 9 & 2 & 95 \\
PIIGS & 528 & 47 & 29 & 604 \\
\hline Fonte: os autores. & & &
\end{tabular}

Os dados secundários foram coletados da base de dados Thomson ${ }^{\circledR}$, considerando as informações relativas ao ano 2011. A utilização da base Thomson ${ }^{\circledR}$ é justificada por ser um fornecedor global de serviços de informação para a comunidade financeira internacional (CENDÓN, 2002), constituindo-se em uma das bases de dados mais importantes do mundo, contendo informações de mais de 91 mil empresas e com alcance superior a 200 países.

A utilização da base de dados escolhida não apresenta entrave para a generalização dos resultados, tendo sido utilizada em outros estudos de abordagens diversas, como os de Daske e Gebhardt (2006), de Doidge, Karolyi e Stulz (2007) e de Klann (2011). A análise dos dados valeu-se do pacote estatístico SPSS ${ }^{\circledR}$, 
aplicando-se a técnica de regressão linear multivariada. Para o desenvolvimento do estudo, foram consideradas as variáveis dependentes e independentes, conforme apresentados no Quadro 1.

Quadro 1 - Variáveis da pesquisa

\begin{tabular}{|c|c|}
\hline Variáveis dependentes & Proxy \\
\hline $\begin{array}{l}\text { 1. Retorno sobre Ativos } \\
\text { (ROA) }\end{array}$ & ROA $=\frac{\text { Lucro Líquido }}{\text { Ativo Total }}$ \\
\hline $\begin{array}{l}\text { 2. Crescimento de Vendas } \\
\text { (CV) }\end{array}$ & $C V=\left(\frac{\text { Vendas do ano corrente }- \text { vendas do ano anterior }}{\text { Vendas do ano anterior }}\right)-1 \times 100$ \\
\hline 3. Giro do Ativo (GA) & $G A=\frac{\text { Vendas }}{\text { Ativo Total }}$ \\
\hline 4. Lucro por Ação (LPA) & $L P A=\frac{\text { Lucro Líquido }}{\text { Número de Ações }}$ \\
\hline $\begin{array}{l}\text { 5. Retorno sobre Patrimônio } \\
\text { Líquido (ROE) }\end{array}$ & $R O E=\frac{\text { Lucro Líquido }}{\text { Patrimônio Líquido }}$ \\
\hline Variáveis independentes & Proxy \\
\hline $\begin{array}{l}\text { 6. Grau de Intangibilidade } \\
2011 \text { (GI) }\end{array}$ & $G I=\frac{\text { Valor de Mercado Total das Ações }}{\text { Patrimônio Líquido Contábil }}$ \\
\hline 7. Segmento econômico & Indústria, utilidades, transportes (mais detalhes no Quadro 2). \\
\hline 8. País de origem & $\begin{array}{l}\text { Espanha (1 - sim; } 0 \text { - não); Grécia (1 - sim; } 0 \text { - não); Irlanda (1 - } \\
\text { sim; } 0 \text { - não); Itália (1 - sim; } 0 \text { - não); Portugal (1 - sim; } 0 \text { - não). } \\
\text { (Mais detalhes no Quadro 3). }\end{array}$ \\
\hline
\end{tabular}

Fonte: os autores.

De acordo com Ahangar (2011), não há uma perspectiva teórica específica ou uma evidência empírica adequada que suporte a superioridade de qualquer medida específica de proxy sobre outras. O Quadro 1 representa as variáveis que foram utilizadas demonstrando as respectivas proxies.

Com base nas variáveis descritas no Quadro 1, o modelo econométrico que verifica a influência do grau de intangibilidade no desempenho das empresas, por país (Tabelas 3 a 7), é demonstrado pelas equações:

$$
\mathrm{ROA}=\beta 0+\beta 1 \mathrm{G} 2011+\beta 2 \mathrm{~A} 1+\beta 3 \mathrm{~A} 2+\beta 4 \text { País }+\varepsilon
$$




$$
\begin{aligned}
& \mathrm{LPA}=\beta 0+\beta 1 \mathrm{GI} 2011+\beta 2 \mathrm{~A} 1+\beta 3 \mathrm{~A} 2+\beta 4 \text { País }+\varepsilon \\
& \mathrm{CV}=\beta 0+\beta 1 \mathrm{GI} 2011+\beta 2 \mathrm{~A} 1+\beta 3 \mathrm{~A} 2+\beta 4 \text { País }+\varepsilon \\
& \mathrm{GA}=\beta 0+\beta 1 \mathrm{GI} 2011+\beta 2 \mathrm{~A} 1+\beta 3 \mathrm{~A} 2+\beta 4 \text { País }+\varepsilon \\
& \mathrm{ROE}=\beta 0+\beta 1 \mathrm{GI} 2011+\beta 2 \mathrm{~A} 1+\beta 3 \mathrm{~A} 2+\beta 4 \text { País }+\varepsilon
\end{aligned}
$$

Já a análise conjunta de todos os países foi elaborada com base nas seguintes equações:

$$
\begin{aligned}
& \mathrm{ROA}=\beta 0+\beta 1 \mathrm{GI} 2011+\beta 2 \mathrm{~A} 1+\beta 3 \mathrm{~A} 2+\beta 4 \mathrm{P} 1+\beta 4 \mathrm{P} 2+\beta 4 \mathrm{P} 3+\beta 4 \mathrm{P} 4+\varepsilon \\
& \mathrm{LPA}=\beta 0+\beta 1 \mathrm{GI} 2011+\beta 2 \mathrm{~A} 1+\beta 3 \mathrm{~A} 2+\beta 4 \mathrm{P} 1+\beta 4 \mathrm{P} 2+\beta 4 \mathrm{P} 3+\beta 4 \mathrm{P} 4+\varepsilon \\
& \mathrm{CV}=\beta 0+\beta 1 \mathrm{GI} 2011+\beta 2 \mathrm{~A} 1+\beta 3 \mathrm{~A} 2+\beta 4 \mathrm{P} 1+\beta 4 \mathrm{P} 2+\beta 4 \mathrm{P} 3+\beta 4 \mathrm{P} 4+\varepsilon \\
& \mathrm{GA}=\beta 0+\beta 1 \mathrm{GI} 2011+\beta 2 \mathrm{~A} 1+\beta 3 \mathrm{~A} 2+\beta 4 \mathrm{P} 1+\beta 4 \mathrm{P} 2+\beta 4 \mathrm{P} 3+\beta 4 \mathrm{P} 4+\varepsilon \\
& \mathrm{ROE}=\beta 0+\beta 1 \mathrm{GI} 2011+\beta 2 \mathrm{~A} 1+\beta 3 \mathrm{~A} 2+\beta 4 \mathrm{P} 1+\beta 4 \mathrm{P} 2+\beta 4 \mathrm{P} 3+\beta 4 \mathrm{P} 4+\varepsilon
\end{aligned}
$$

As variáveis ROA, LPA, CV, GA, ROE e GI2011 estão descritas no Quadro 1. As variáveis A1 e A2 foram operacionalizadas conforme consta no Quadro 2 e as variáveis $\mathrm{P} 1, \mathrm{P} 2, \mathrm{P} 3$ e P4, conforme está descrito no Quadro 3.

\section{APRESENTAÇÃO E ANÁLISE DOS RESULTADOS}

A análise inicia-se com a estatística descritiva sobre o grau de intangibilidade, conforme a Tabela 2. Os dados demonstram que o valor mínimo foi constatado em empresas da Itália e o valor máximo, em empresas da Espanha. O menor desvio padrão foi constatado nas empresas portuguesas e o maior, em empresas da Itália, contudo, as variações não são elevadas.

Tabela 2 - Estatística descritiva GI 2011

\begin{tabular}{crrrr}
\hline País & Mínimo & Máximo & Média & Desvio Padrão \\
\hline Portugal & $-0,619$ & 7,181 & 1,203 & 1,656 \\
Irlanda & $-4,906$ & 15,614 & 2,294 & 3,493 \\
Itália & $-65,832$ & 14,596 & 0,999 & 5,169 \\
Grécia & $-7,559$ & 18,471 & 0,772 & 1,906 \\
Espanha & $-0,717$ & 24,038 & 1,954 & 3,199 \\
PIIGS & $-65,832$ & 24,038 & 1,166 & 3,602 \\
\hline Fonte: os autores & & & &
\end{tabular}

Fonte: os autores. 
As empresas da Grécia apresentaram a menor média de intangibilidade, com desempenho abaixo de 1 , ou seja, o valor contábil se mostrou maior que o valor de mercado. A média das empresas italianas está muito próxima da unidade. As empresas de Portugal, Espanha e Irlanda apresentaram valores médios superiores a 1, indicando que nesses países, em média, os valores de mercado (considerando a valorização das ações) são maiores que o valor contábil do respectivo patrimônio líquido.

$\mathrm{Na}$ aplicação da técnica de regressão linear múltipla, foram testados os pressupostos da multicolinearidade, da autocorrelação dos resíduos e da homocedasticidade. A Variance Inflation Factor (VIF) é uma medida de quanto a variância de cada coeficiente de regressão estimado aumenta em decorrência da colinearidade. O teste Durbin-Watson $(D W)$ aponta a possível existência de problema de alta correlação entre os resíduos das variáveis utilizadas (FÁVERO et al., 2009). Os resultados dos testes realizados apresentaram índices dentro dos parâmetros aceitáveis, conforme pressuposto por Hair et al. (2009). O teste Pesarán-Pesarán indicou normalidade no comportamento dos resíduos, não se constatando presença de heterocedasticidade (CUNHA; COELHO, 2012).

Para testar as hipóteses do estudo, foi utilizada a técnica de regressão linear multivariada com variáveis relativas ao ano 2011. Inicialmente, foram utilizadas como variáveis independentes o GI e os cinco países investigados; por exemplo, ao utilizar Portugal, considerou-se a variável dummy 1 para as empresas desse país e 0 para as empresas dos demais países, e assim sucessivamente para os demais países.

Quanto às atividades, considerando-se a presença de três setores econômicos investigados (indústria, utilidades e transportes), utilizaram-se duas variáveis dummies, construídas com base em Fávero et al. (2009), conforme é demonstrado no Quadro 2.

Quadro 2 - Dummies utilizadas para a variável de segmento econômico

\begin{tabular}{|c|c|c|}
\hline \multirow{2}{*}{ Setor econômico } & \multicolumn{2}{|c|}{ Dummies } \\
\cline { 2 - 3 } & A1 & A2 \\
\hline Indústria & 0 & 0 \\
Utilidades & 1 & 0 \\
Transportes & 0 & 1 \\
\hline
\end{tabular}

Fonte: adaptado de Fávero et al. (2009).

Com essa medida, o segmento indústria passa a ser a variável de controle, escolhida em razão de ser a atividade com o maior número de empresas. A partir 
dos procedimentos descritos, foram geradas regressões lineares múltiplas para cada variável independente, podendo-se verificar a influência de cada atividade em separado sobre o desempenho econômico.

$\mathrm{Na}$ Tabela 3, são apresentados os resultados da regressão linear múltipla mostrando a relação entre as variáveis dependentes (ROA, LPA, CV, GA, ROE) e as variáveis independentes, considerando-se Portugal o país ao qual se atribuiu a dummy 1.

Os resultados apresentados na Tabela 3 indicam relação estatisticamente significativa ao nível de $1 \%$ da variável dependente ROE e de $5 \%$ das variáveis dependentes ROA, CV e GA, com as variáveis independentes consideradas. A variável LPA não apresentou relação estatística significante com as demais variáveis.

Tabela 3 - Resultados da regressão linear múltipla 2011 (Portugal)

\begin{tabular}{|c|c|c|c|c|c|c|c|c|c|c|}
\hline ROA & & ROA & & LPA & & $\mathrm{CV}$ & & GA & & ROE \\
\hline R2 ajustado & & 0,010 & & $-0,002$ & & 0,009 & & 0,015 & & 0,348 \\
\hline $\mathrm{F}$ & & 2,459 & & 0,648 & & 2,381 & & 3,283 & & 81,464 \\
\hline Significância & & $\star \star 0,044$ & & 0,628 & & $\star \star 0,050$ & & $\star \star 0,011$ & & $\star 0,000$ \\
\hline Variáveis & $\begin{array}{r}\text { Coef. } \\
\text { B. }\end{array}$ & $\mathbf{t}$ & $\begin{array}{r}\text { Coef. } \\
\text { B. }\end{array}$ & $\mathbf{t}$ & $\begin{array}{r}\text { Coef. } \\
\text { B. }\end{array}$ & $\mathbf{T}$ & $\begin{array}{r}\text { Coef. } \\
\text { B }\end{array}$ & $\mathbf{t}$ & Coef. & $\mathbf{t}$ \\
\hline (Constant) & $-0,049$ & $\star_{-}-5,526$ & $-0,420$ & $-1,301$ & 2,200 & 1,286 & 0,774 & $\star 22,014$ & 0,171 & $\star \star 2,807$ \\
\hline GI 2011 & 0,006 & $\star 2,717$ & 0,087 & 1,114 & 0,505 & 1,220 & 0,014 & $\star \star \star 1,697$ & $-0,265$ & $\star-18,101$ \\
\hline A1 & 0,031 & 1,092 & 0,753 & 0,722 & 10,762 & $\star \star 1,946$ & $-0,221$ & $\star \star \star-1,948$ & $-0,078$ & $-0,395$ \\
\hline A2 & $-0,004$ & $-0,100$ & 0,512 & 0,381 & 15,181 & $\star \star 2,135$ & $-0,369$ & $\star \star-2,526$ & $-0,137$ & $\begin{array}{r}-0,542 \\
0,7510,751\end{array}$ \\
\hline Portugal & 0,028 & 0,913 & 0,884 & 0,797 & $-2,336$ & $-0,398$ & $-0,096$ & $-0,798$ & 0,157 & 0,751 \\
\hline
\end{tabular}

Fonte: os autores.

Nota: $\mathrm{n}=604$. Significância: ${ }^{\star}$ ao nível de $1 \%$; $\star \star$ ao nível de $5 \%$; $\star \star \star$ ao nível de $10 \%$.

Portugal $=1$. Outros países $=0$. A $1=$ Utilidades. A2 $=$ Transportes.

Em relação ao grau de intangibilidade, constata-se a presença de relação positiva e estatisticamente significativa ao nível 1\% com ROA e em 10\% com GA. Esse resultado indica que quanto maior o grau de intangibilidade das empresas, maior o retorno sobre os ativos e também maior o giro dos ativos. Também foi observada relação negativa e estatisticamente significativa ao nível 1\% com o ROE, indicando que empresas com maior intangibilidade geram menos retorno sobre o patrimônio líquido. 
Quanto ao país, nota-se que Portugal como variável independente não mantém relação estatisticamente significativa (nem positiva nem negativa) com nenhuma variável de desempenho.

As atividades industriais em Portugal proporcionaram maior retorno sobre o patrimônio líquido e maior giro sobre ativos em relação às atividades de utilidades e transportes. Entretanto, as atividades de utilidades e transportes apresentaram melhores resultados quanto ao lucro por ação e ao crescimento de vendas. Em relação ao ROA, as atividades industriais apresentaram resultado superior à atividade de transportes e inferior em relação às atividades de utilidades.

A Tabela 4 apresenta os resultados da regressão linear múltipla mostrando a relação entre as variáveis dependentes e independentes, considerando a Irlanda como o país que recebeu a dummy 1 e os demais países, a dummy 0 .

Tabela 4 - Resultados da regressão linear múltipla 2011 (Irlanda)

\begin{tabular}{|c|c|c|c|c|c|c|c|c|c|c|}
\hline ROA & & ROA & & LPA & & $\mathrm{CV}$ & & GA & & ROE \\
\hline$\overline{\mathrm{R} 2}$ ajustado & & 0,011 & & $-0,002$ & & 0,034 & & 0,017 & & 0,353 \\
\hline $\mathrm{F}$ & & 2,629 & & 0,686 & & 6,291 & & 3,543 & & 83,097 \\
\hline Significância & & $\star \star 0,034$ & & 0,602 & & $\star_{0} 0,000$ & & $\star_{0,007}$ & & $\star_{0} 0,000$ \\
\hline Variáveis & $\begin{array}{r}\text { Coef. } \\
\text { B. }\end{array}$ & $\mathbf{t}$ & $\begin{array}{r}\text { Coef. } \\
\text { B. }\end{array}$ & $\mathbf{t}$ & $\begin{array}{r}\text { Coef. } \\
\mathrm{B} . \\
\end{array}$ & $\mathbf{T}$ & $\begin{array}{r}\text { Coef. } \\
\text { B } \\
\end{array}$ & t & Coef. & t \\
\hline (Constant) & $-0,050$ & $\star_{-5,603}$ & $-0,422$ & $-1,313$ & 0,580 & 0,344 & 0,757 & $\star 21,638$ & 0,152 & $\star \star 2,522$ \\
\hline GI 2011 & 0,006 & $\star 2,600$ & 0,081 & 1,032 & 0,363 & 0,886 & 0,013 & 1,580 & $-0,268$ & $\star_{-}-18,198$ \\
\hline A1 & 0,035 & 1,217 & 0,855 & 0,820 & 11,831 & $\star \star 2,168$ & $-0,219$ & $\begin{array}{r}\star \star \star \star \\
1,926\end{array}$ & $-0,045$ & $-0,228$ \\
\hline A2 & $-0,007$ & $-0,193$ & 0,411 & 0,307 & 14,411 & $\star \star 2,055$ & $-0,369$ & $\star \star-2,528$ & $-0,166$ & $-0,661$ \\
\hline Irlanda & 0,038 & 1,227 & 0,996 & 0,887 & 23,187 & $\star 3,944$ & 0,157 & 1,287 & 0,462 & $\star \star 2,190$ \\
\hline
\end{tabular}

Fonte: os autores.

Nota: $\mathrm{n}=604$. Significância: ${ }^{\star}$ ao nível de $1 \%$; $\star \star$ ao nível de $5 \%$; ${ }^{\star \star \star}$ ao nível de $10 \%$.

Irlanda $=1$. Outros países $=0$. A $1=$ Utilidades. A2 $=$ Transportes.

Os resultados apresentados na Tabela 4 indicam relação estatisticamente significativa ao nível de $1 \%$ das variáveis dependentes CV, GAe ROE e de $5 \%$ da variável dependente ROA, com as variáveis independentes consideradas. A variável LPA não apresentou relação estatística significante com as demais variáveis. Em relação ao grau de intangibilidade, constata-se a presença de relação positiva e estatisticamente significativa ao nível 1\% com ROA e negativa e estatisticamente significativa ao nível $1 \%$ com o ROE, indicando que empresas com maior intangibilidade geram mais retornos sobre os ativos e menos retorno sobre o patrimônio líquido. 
Quanto ao país, nota-se que a Irlanda como variável independente demonstra relação estatisticamente significativa com CV (1\%) e com ROE (5\%); com as demais variáveis apresenta coeficientes positivos, porém, não significativos.

Os resultados indicam que nas empresas irlandesas as atividades industriais proporcionaram maior retorno sobre o patrimônio líquido e maior giro sobre os ativos, em relação às atividades de utilidades e transportes; entretanto, estas apresentam melhores resultados quanto ao lucro por ação e ao crescimento de vendas. O ROA apresentou resultados mistos, em que as atividades industriais apresentaram resultados superiores à atividade de transportes e inferior em relação às atividades de utilidades.

A Tabela 5 apresenta os resultados da regressão linear múltipla, mostrando a relação entre variáveis de desempenho (ROA, LPA, CV, GA, ROE) com o grau de intangibilidade, os segmentos econômicos e o país-sede, considerando a Itália o país que recebeu a dummy 1 .

Tabela 5 - Resultados da regressão linear múltipla 2011 (Itália)

\begin{tabular}{|c|c|c|c|c|c|c|c|c|c|c|}
\hline ROA & & ROA & & LPA & & $\mathrm{CV}$ & & GA & & ROE \\
\hline R2 ajustado & & 0,008 & & $-0,003$ & & 0,012 & & 0,015 & & 0,353 \\
\hline $\mathrm{F}$ & & 2,247 & & 0,530 & & 2,800 & & 3,337 & & 83,229 \\
\hline Significância & & $\star \star \star 0,063$ & & 0,714 & & $\star \star 0,025$ & & $\star 0,010$ & & $\star_{0} 0,000$ \\
\hline Variáveis & $\begin{array}{r}\text { Coef. } \\
\text { B. }\end{array}$ & $\mathbf{t}$ & $\begin{array}{r}\text { Coef. } \\
\text { B. }\end{array}$ & $\mathbf{t}$ & $\begin{array}{r}\text { Coef. } \\
\text { B. }\end{array}$ & $\mathbf{T}$ & $\begin{array}{r}\text { Coef. } \\
\text { B }\end{array}$ & $\mathbf{t}$ & Coef. & $t$ \\
\hline (Constant) & $-0,048$ & $\star_{-} 4,616$ & $-0,441$ & $-1,183$ & 0,606 & 0,307 & 0,747 & $\star 18,394$ & 0,096 & 1,365 \\
\hline GI 2011 & 0,006 & $\star 2,714$ & 0,088 & 1,128 & 0,526 & 1,271 & 0,015 & $\star \star \star 1,731$ & $-0,264 \star$ & $-17,983$ \\
\hline A1 & 0,033 & 1,143 & 0,777 & 0,744 & 10,159 & $\star \star \star 1,839$ & $-0,233$ & $\star \star-2,054$ & $-0,097$ & $-0,494$ \\
\hline A2 & $-0,055$ & $-0,148$ & 0,498 & 0,370 & 16,149 & $\star \star 2,270$ & $-0,351$ & $\star \star-2,398$ & $-0,099$ & $-0,394$ \\
\hline Itália & 0,001 & 0,042 & 0,245 & 0,407 & 4,280 & 1,344 & 0,060 & 0,922 & 0,256 & 2,267 \\
\hline
\end{tabular}

Fonte: os autores.

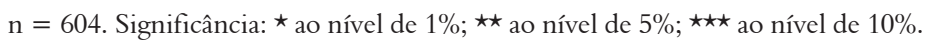

Itália $=1$. Outros países $=0$. A $1=$ Utilidades. A2 $=$ Transportes.

Os resultados mostrados na Tabela 5 indicam relação estatisticamente significativa ao nível de $1 \%$ das variáveis dependentes GA e ROE, de $5 \%$ da variável dependente $\mathrm{CV}$ e de $10 \%$ da variável dependente ROA, com as variáveis independentes utilizadas. A variável LPA não apresentou relação estatística significante com as demais variáveis.

Quanto ao grau de intangibilidade, verifica-se a presença de relação positiva e estatisticamente significativa ao nível de $1 \%$ com ROA e de $10 \%$ com GA, além 
de relação negativa e estatisticamente significativa ao nível de $1 \%$ com o ROE, indicando que empresas com maior intangibilidade possuem maior retorno sobre ativos, maior giro dos ativos e menos retorno sobre o patrimônio líquido.

Em relação ao país, nota-se que a Itália como variável independente não apresenta relação estatisticamente significativa com nenhuma variável de desempenho (situação semelhante à de Portugal), indicando que a presença das empresas nesses países não está relacionada com desempenho mais elevado.

Os resultados indicam que as empresas italianas com atividades de utilidades e de transportes apresentam resultados melhores quanto ao lucro por ação e ao crescimento por vendas. De outro modo, as atividades industriais proporcionaram maior retorno sobre o patrimônio líquido e maior giro sobre os ativos. Os resultados mistos em relação ao ROA foram novamente constatados, em que as atividades industriais apresentaram resultados superiores à atividade de transportes e inferior em relação às atividades de utilidades.

A Tabela 6 apresenta os resultados da regressão linear múltipla, mostrando a relação entre as variáveis, considerando a Grécia o país ao qual se atribuiu a dummy 1.

Tabela 6 - Resultados da regressão linear múltipla 2011 (Grécia)

\begin{tabular}{|c|c|c|c|c|c|c|c|c|c|c|}
\hline ROA & & ROA & & LPA & & $\mathrm{CV}$ & & GA & & ROE \\
\hline R2 ajustado & & 0,018 & & 0,019 & & 0,048 & & 0,015 & & 0,374 \\
\hline $\mathrm{F}$ & & 3,799 & & 3,888 & & 8,580 & & 3,225 & & 91,179 \\
\hline Significância & & $\star_{0,005}$ & & $\star 0,004$ & & $\star_{0,000}$ & & $\star \star 0,012$ & & $\star_{0,000}$ \\
\hline Variáveis & $\begin{array}{r}\text { Coef. } \\
\text { B. }\end{array}$ & $t$ & $\begin{array}{r}\text { Coef. } \\
\text { B. }\end{array}$ & $\mathbf{t}$ & $\begin{array}{r}\text { Coef. } \\
\text { B. }\end{array}$ & $\mathbf{T}$ & $\begin{array}{r}\text { Coef. } \\
\text { B }\end{array}$ & $\mathbf{t}$ & Coef. & $\mathbf{t}$ \\
\hline (Constant) & $-0,032$ & $\star_{-2,988}$ & 0,470 & 1,226 & 7,907 & $\star 3,925$ & 0,783 & $\star 18,542$ & 0,395 & $\star 5,516$ \\
\hline GI 2011 & 0,005 & $\star \star 2,525$ & 0,065 & 0,833 & 0,346 & 0,851 & 0,014 & $\star \star \star 1,642$ & $-0,271$ & $\star_{-}-18,729$ \\
\hline A1 & 0,027 & 0,925 & 0,458 & 0,443 & 8,187 & 1,507 & $-0,233$ & $\star \star-2,049$ & $-0,157$ & $-0,816$ \\
\hline A2 & 0,008 & 0,212 & 1,175 & 0,877 & 20,459 & $\star 2,908$ & $-0,349$ & $\star \star-2,363$ & 0,038 & 0,154 \\
\hline Grécia & $-0,040$ & $\star \star-2,473$ & $-2,154$ & $\star_{-}-3,681-$ & $-15,231$ & $\star_{-4,957}$ & $-0,041$ & $-0,641$ & $-0,554$ & $\star \star-5,075$ \\
\hline
\end{tabular}

Fonte: os autores.

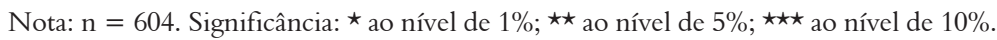

Grécia $=1$. Outros países $=0$. A1 $=$ Utilidades. A2 $=$ Transportes.

A Tabela 6 indica a presença de relação estatisticamente significativa ao nível de $1 \%$ das variáveis dependentes ROA, LPA, CV e ROE e de $5 \%$ da variável dependente GA, com as variáveis independentes utilizadas. Quanto ao grau de intangibilidade, verifica-se a presença de relação positiva e estatisticamente 
significativa ao nível de 5\% com ROA e de $10 \%$ com GA, além de relação negativa e estatisticamente significativa ao nível de 1\% com o ROE, indicando que empresas com maior intangibilidade possuem maior retorno sobre ativos, maior giro dos ativos e menor retorno sobre o patrimônio líquido.

Em relação ao país, a Grécia como variável independente apresenta somente relações negativas com as variáveis de desempenho, sendo estatisticamente significativa ao nível de 1\% com LPA, CV e ROE e de 5\% com ROA. Conforme constatado anteriormente na Tabela 6, as empresas da Grécia apresentaram, em média, os menores índices de grau de intangibilidade, repercutindo desempenhos econômicos inferiores se comparados às empresas dos demais países.

Os resultados indicam que na Grécia as empresas com atividades de utilidades e de transportes apresentaram resultados melhores quanto ao lucro por ação, ao crescimento das vendas e ao retorno sobre ativos. De outro modo, as atividades industriais proporcionaram maior giro sobre ativos. Quanto ao retorno sobre o patrimônio líquido, os resultados mostraram-se mistos, em que as atividades industriais apresentaram resultados superiores às atividades de utilidades e inferiores em relação às atividades de transportes.

A Tabela 7 apresenta os resultados da regressão linear múltipla com a relação entre as variáveis ROA, LPA, CV, GA, ROE e o grau de intangibilidade, os segmentos econômicos e o país-sede, considerando a Espanha o país de dummy 1.

Tabela 7 - Resultados da regressão linear múltipla 2011 (Espanha)

\begin{tabular}{|c|c|c|c|c|c|c|c|c|c|c|}
\hline \multicolumn{2}{|c|}{ ROA } & \multicolumn{2}{|l|}{ ROA } & \multicolumn{2}{|l|}{ LPA } & \multicolumn{2}{|l|}{$\mathrm{CV}$} & \multicolumn{2}{|l|}{ GA } & \multirow{2}{*}{$\frac{\text { ROE }}{0,350}$} \\
\hline$\overline{\mathrm{R} 2}$ ajustado & & 0,13 & & 0,013 & & 0,017 & & 0,015 & & \\
\hline $\mathrm{F}$ & & 2,977 & & 2,919 & & 3,621 & & 3,238 & & 82,212 \\
\hline Significância & & $\star \star 0,019$ & & $\star \star 0,021$ & & $\star_{0,006}$ & & $\star \star 0,012$ & & $\star_{0,000}$ \\
\hline Variáveis & $\begin{array}{r}\text { Coef. } \\
\mathrm{B} .\end{array}$ & $\mathbf{t}$ & $\begin{array}{r}\text { Coef. } \\
\mathrm{B} . \\
\end{array}$ & $\mathbf{t}$ & $\begin{array}{r}\text { Coef. } \\
\text { B. }\end{array}$ & $\mathbf{t}$ & $\begin{array}{r}\text { Coef. } \\
\mathrm{B} \\
\end{array}$ & $\mathbf{t}$ & $\begin{array}{r}\text { Coef. } \\
\mathrm{B}\end{array}$ & $\mathbf{t}$ \\
\hline (Constant) & $-0,053$ & $\star-5,722$ & $-0,716$ & $\star \star-2,158$ & 0,673 & 0,381 & 0,776 & $\star 21,304$ & 0,147 & $\star \star 2,338$ \\
\hline GI 2011 & 0,006 & $\star \star 2,554$ & 0,065 & 0,832 & 0,420 & 1,014 & 0,015 & $\star \star \star 1,752$ & $-0,267$ & $\star_{-}-18,110$ \\
\hline A1 & 0,031 & 1,093 & 0,695 & 0,672 & 10,212 & $\star \star \star 1,857$ & $-0,224$ & $\star \star-1,975$ & $-0,079$ & $-0,404$ \\
\hline A2 & $-0,001$ & $-0,035$ & 0,737 & 0,553 & 16,436 & $\star \star 2,319$ & $-0,369$ & $\star \star-2,525$ & $-0,120$ & $-0,476$ \\
\hline Espanha & 0,036 & $\star \star \star 1,697$ & 2,402 & $\star 3,113$ & 9,216 & $\star \star 2,245$ & $-0,057$ & $-0,678$ & 0,231 & 1,582 \\
\hline
\end{tabular}

Fonte: os autores.

Nota: $\mathrm{n}=604$. Significância: ${ }^{\star}$ ao nível de $1 \%$; ${ }^{\star}$ ao nível de $5 \%$; ${ }^{\star \star \star}$ ao nível de $10 \%$.

Espanha $=1$. Outros países $=0$. A $1=$ Utilidades. A2 $=$ Transportes. 
A Tabela 7 indica a presença de relação estatisticamente significativa ao nível de 1\% das variáveis dependentes CV e ROE e de 5\% das variáveis dependentes ROA, LPA e GA, com as variáveis independentes utilizadas. Quanto ao grau de intangibilidade, verifica-se a presença de relação positiva e estatisticamente significativa ao nível de 5\% com ROA e de $10 \%$ com GA, além de relação negativa e estatisticamente significativa ao nível de $1 \%$ com o ROE, indicando que empresas com maior intangibilidade possuem maior retorno sobre ativos, maior giro dos ativos e menor retorno sobre o patrimônio líquido.

Em relação ao país, a Espanha como variável independente apresenta relação positiva e estatisticamente significativa ao nível de 1\% com LPA, de 5\% com CV e de $10 \%$ com ROA.

$\mathrm{Na}$ Espanha, as empresas com atividades de utilidades e de transportes apresentaram resultados melhores quanto ao lucro por ação e ao crescimento das vendas. De outro modo, as atividades industriais proporcionaram maior giro sobre os ativos e maior retorno sobre o patrimônio líquido. Quanto ao retorno sobre ativos, os resultados mostraram-se alternados.

Para considerar a presença dos cinco países investigados simultaneamente, utilizaram-se quatro variáveis dummies (n-1), construídas com base em Fávero et al. (2009), conforme demonstrado no Quadro 3.

Quadro 3 - Dummies utilizadas para a variável de segmento econômico

\begin{tabular}{|c|c|c|c|c|}
\hline \multirow{2}{*}{ Países } & \multicolumn{4}{|c|}{ Dummies } \\
\cline { 2 - 5 } Grécia & P1 & P2 & P3 & P4 \\
Portugal & 1 & 0 & 0 & 0 \\
Irlanda & 0 & 1 & 0 & 0 \\
Itália & 0 & 0 & 1 & 0 \\
Espanha & 0 & 0 & 0 & 1 \\
\hline Fonte: adaptado de Fávero et al. (2009).
\end{tabular}

Com essa medida, a Grécia passa a ser a variável de controle, escolhida em razão de ser o país com o maior número de empresas na amostra investigada. $\mathrm{Na}$ Tabela 8 apresentam-se os resultados da regressão linear múltipla com a relação entre variáveis ROA, LPA, CV, GA, ROE e o grau de intangibilidade, os segmentos econômicos e os cinco países-sede. 
Tabela 8 - Resultados da regressão linear múltipla 2011 (PIIGS)

\begin{tabular}{|c|c|c|c|c|c|c|c|c|c|c|}
\hline ROA & & ROA & & LPA & & $\mathrm{CV}$ & & GA & & ROE \\
\hline R2 ajustado & & 0,017 & & 0,22 & & 0,061 & & 0,014 & & 0,373 \\
\hline $\mathrm{F}$ & & 2,515 & & 2,919 & & 6,605 & & 2,256 & & 52,156 \\
\hline Significância & & $\star \star 0,015$ & & $\star_{0,005}$ & & $\star_{0} 0,000$ & & $\star \star 0,028$ & & $\star_{0,000}$ \\
\hline Variáveis & $\begin{array}{r}\text { Coef. } \\
\text { B. }\end{array}$ & $\mathbf{t}$ & $\begin{array}{r}\text { Coef. } \\
\text { B. }\end{array}$ & $\mathbf{t}$ & $\begin{array}{r}\text { Coef. } \\
\text { B. }\end{array}$ & $\mathbf{t}$ & $\begin{array}{r}\text { Coef. } \\
\text { B }\end{array}$ & $\mathbf{t}$ & Coef. & $t$ \\
\hline (Constant) & $-0,072$ & $\star-5,433$ & $-1,675$ & $\star-3,531$ & $-7,161$ & $\star_{-}-2,889$ & 0,743 & $\star 14,192$ & $-0,157$ & $\star \star \star-1,771$ \\
\hline GI 2011 & 0,005 & $\star \star 2,350$ & 049 & 0,632 & 0,215 & 0,528 & 0,014 & 1,620 & $-0,272$ & $\star_{-}-18,684$ \\
\hline A1 & 0,028 & 0,963 & 0,471 & 0,455 & 9,656 & $\star \star \star 1,783$ & $-0,220$ & $\star \star \star-1,927$ & $-0,139$ & $-0,719$ \\
\hline A2 & 0,007 & 0,191 & 1,208 & 0,901 & 19,026 & $\star 2,717$ & $-0,364$ & $\star \star-2,463$ & 0,019 & 0,077 \\
\hline P1 & 0,052 & 1,613 & 2,225 & $\star \star \star 1,925$ & 7,532 & 1,247 & $-0,065$ & $-0,508$ & 0,502 & $\star \star 2,322$ \\
\hline P2 & 0,060 & $\star \star \star 1,865$ & 2,273 & $\star \star \star 1,953$ & 30,984 & $\star 5,098$ & 0,171 & 1,330 & 0,770 & $\star 3,538$ \\
\hline P3 & 0,026 & 1,389 & 1,535 & $\star \star 2,287$ & 12,353 & $\star 3,523$ & 0,064 & 0,869 & 0,519 & $\star 4,135$ \\
\hline P4 & 0,057 & $\star \star 2,399$ & 3,410 & $\star 4,029$ & 17,482 & $\star 3,954$ & $-0,023$ & -0.244 & 0,550 & $\star 3,476$ \\
\hline
\end{tabular}

Fonte: os autores.

Nota: $\mathrm{n}=604$. Significância: * ao nível de $1 \%$; $\star \star$ ao nível de $5 \%$; ${ }^{\star \star \star}$ ao nível de $10 \%$.

P1 = Portugal; P2 = Irlanda; P3 = Itália; P4 = Espanha; A1 = Utilidades; A2 = Transportes.

Variáveis de controle: Grécia (país); Indústria (atividade).

A Tabela 8 indica a presença de relação estatisticamente significativa ao nível de $1 \%$ das variáveis dependentes LPA, CV e ROE e de 5\% das variáveis dependentes ROA e GA, com as variáveis independentes utilizadas. Quanto ao grau de intangibilidade, verifica-se a presença de relação positiva e estatisticamente significativa ao nível de 5\% com o ROA e relação negativa e estatisticamente significativa ao nível de $1 \%$ com o ROE, indicando que no conjunto total das empresas dos cinco países analisados, aquelas com maior intangibilidade possuem maior retorno sobre ativos e menor retorno sobre o patrimônio líquido.

No comparativo entre os segmentos econômicos, constata-se na Tabela 8 o desempenho superior das atividades de utilidades e transportes em relação às atividades industriais, nas variáveis ROA, LPA e CV. As atividades industriais tiveram melhor desempenho sobre as demais atividades na variável GA. Quanto ao ROE, as atividades industriais apresentaram desempenho inferior às atividades de transportes e superior às de utilidades.

Em relação aos países, observa-se que Portugal apresenta relação estatisticamente significante com a variável ROE (5\%) e com LPA (10\%). A Irlanda mostra relação estatística significante ao nível de $1 \%$ com CV e ROE e de $10 \%$ com ROA e LPA. A Itália apresenta relação significante positiva ao nível de $1 \%$ com 
CV e ROE e de $10 \%$ com LPA. Já em relação à Espanha, nota-se relação positiva e estatisticamente significativa com LPA, CV e ROE (1\%) e de 5\% com ROA.

No comparativo entre os países, os resultados da Tabela 8 indicam que as empresas da Grécia, de modo geral, apresentam resultados inferiores às empresas dos demais países em todas as variáveis de desempenho, exceção feita às empresas de Portugal e Espanha em relação ao giro dos ativos.

Após a aplicação da técnica de regressão linear multivariada sob os seis tipos de análises, pode-se constatar que a variável independente GI apresentou diversas relações significantes com as variáveis de desempenho (dependentes). Com a variável ROA, mostrou-se positiva e estatisticamente significativa em todas as análises (a 1\% ou 5\%) e com ROE negativa e estatisticamente significativa em todas as análises (a 1\%). Em relação à variável GA, observaram-se resultados mistos (significativos e não significativos). As variáveis LPA e CV não se mostraram significantes com o GI em nenhuma das análises.

Os resultados apresentados nas análises realizadas não permitem confirmar a hipótese $\mathrm{H}_{0}$, aceitando-se a hipótese $\mathrm{H}_{1}$, ou seja, existe relação estatisticamente significativa entre o grau de intangibilidade das empresas de Portugal, Irlanda, Itália, Grécia e Espanha e o desempenho econômico das empresas investigadas, com o uso de variáveis relativas ao ano 2011.

Essa constatação é reforçada pelos resultados apresentados pelas empresas gregas, em que foram verificadas apenas relações estatisticamente negativas com as variáveis de desempenho, visto que as empresas desse país possuem grau de intangibilidade de 0,772 , isto é, o valor contábil do patrimônio líquido é maior que o valor de mercado dessas organizações.

Outro reforço à aceitação da $\mathrm{H}_{1}$ é o desempenho das empresas italianas, em que a variável país apresentou relação positiva com todas as variáveis de desempenho, porém, nenhuma com significância estatística. Nessas empresas, em média, o grau de intangibilidade é de 0,999 , isto é, o valor de mercado das empresas é praticamente igual ao valor contábil. Já as empresas irlandesas apresentaram os maiores índices de intangibilidade e, de modo geral, os melhores índices de desempenho econômico entre o conjunto total de empresas investigadas.

Os resultados obtidos neste estudo podem ser relacionados com aqueles obtidos em outras investigações utilizando o mesmo procedimento para cálculo da intangibilidade. Perez e Famá (2006) investigaram centenas de empresas não financeiras norte-americanas, os resultados mostraram-se significativos e 
demonstram a existência de importantes diferenças de desempenho entre as empresas intangível-intensivas e as empresas tangível-intensivas.

No contexto brasileiro, Couto (2009) investigou a relação entre os ativos intangíveis e o desempenho econômico das empresas brasileiras listadas no nível de governança corporativa do novo mercado, encontrando que a relação é significativa para a maioria das empresas. Usando a mesma métrica para cálculo da intangibilidade, Ritta e Ensslin (2009) investigaram as empresas brasileiras que compõem a carteira teórica do Ibovespa, e as análises de regressão mostraram-se significativas e apontam uma relação positiva entre os ativos intangíveis e as variáveis financeiras propostas, constatando-se que os investimentos em intangíveis proporcionam aumento de receitas, adição de valor ao patrimônio líquido e valorização das ações.

Os resultados do presente estudo corroboram a influência dos ativos intangíveis sobre o desempenho das organizações, em que o GI consistente abaixo de zero gerou resultados econômicos menos satisfatórios. Por outro lado, o GI consistente acima de zero gerou resultados econômicos superiores.

\section{CONSIDERAÇÕES FINAIS}

A análise dos dados foi realizada pelo uso de regressão linear multivariada, em que foram consideradas como variáveis dependentes o grau de intangibilidade e dummies para representar os países e os segmentos econômicos e para explicar o comportamento das variáveis de desempenho.

A análise descritiva da variável GI permitiu verificar que as empresas da Irlanda apresentam, em média, o maior grau de intangibilidade (2,294), seguidas pelas empresas da Espanha (1,699), de Portugal (1,2031), da Itália $(0,999)$ e da Grécia $(0,772)$. Embora os cinco países tenham experimentado desde 2008 um período de forte crise econômica, na Grécia, as evidências mostram impactos mais contundentes que persistem até o momento atual, o que ajuda a explicar a maior desvalorização do valor de mercado das empresas.

A análise das empresas investigadas sob a ótica do retorno sobre ativos, crescimento de vendas, giro do ativo, lucro por ação e retorno sobre o patrimônio líquido indicou que, no ano 2011, quanto maior era o grau de intangibilidade das empresas, em geral, melhor foi o desempenho das variáveis de resultado.

De modo geral, pode-se constatar que o GI possui relação positiva e estatisticamente significativa com o aumento do ROA e negativa e estatisticamente 
significativa com o ROE. Em todas as análises realizadas não foi constatada relação estatisticamente significativa entre as variáveis de grau de intangibilidade e o lucro por ação, além das variáveis de grau de intangibilidade e o crescimento das vendas, indicando que os investimentos em ativos intangíveis não repercutiram sobre o desempenho de curto prazo. Em relação às análises entre grau de intangibilidade e giro do ativo, todas se mostraram positivas, alternando relações significativas e não significativas.

A influência do grau de intangibilidade sobre o desempenho pode ser observada, de modo específico, analisando-se as empresas da Irlanda. Esse grupo apresentou a maior média no grau de intangibilidade e, do mesmo modo, os melhores indicadores de desempenho. Por outro lado, as empresas gregas, que apresentaram a menor média no grau de intangibilidade, obtiveram, de modo geral, os menores indicadores de desempenho. As empresas italianas, com grau de intangibilidade próximo a 1, apresentaram indicadores com desempenho intermediário. $\mathrm{O}$ desempenho observado nos diferentes grupos de empresas estudadas reforça o argumento da influência da intangibilidade sobre o desempenho das organizações, também verificado em ambientes com vulnerabilidade econômica.

A partir dos resultados encontrados é possível rejeitar a hipótese $\mathrm{H}_{0}$ e aceitar a hipótese $\mathrm{H}_{1}$, ou seja, existe relação entre o grau de intangibilidade e o desempenho econômico na amostra investigada. Os pressupostos teóricos da capacidade estratégica e competitiva dos ativos intangíveis ficaram evidenciados também no cenário de turbulência econômica, ao se constatar que, na maioria das variáveis utilizadas, o valor de mercado das empresas tem correspondência nos resultados obtidos.

\section{REFERÊNCIAS}

AHANGAR, R. G. The relationship between intellectual capital and financial performance: An empirical investigation in an Iranian company. African Journal of Business Management, v. 5, p. 88-95, 2011.

ARCHIBUGI, D.; FILIPPETTI, A.; FRENZ, M. The impact of the economic crisis on innovation: Evidence from Europe. Technological Forecasting \& Social Change, v. 80, p. 1247-1260, 2013.

ARRIGHETTI, A.; LANDINI, F.; LASAGNI, A. Intangible assets and firm heterogeneity: evidence from Italy. Research Policy, v. 43, p. 202-213, 2014. 
AXTLE-ORTIZ, M. A. Perceiving the value of intangible assets in context. Journal of Business Research, i. 66, p. 417-424, 2013.

BONTIS, N.; KEOW, W. C. C.; RICHARDSON, S. Intellectual Capital and Business Performance in Malaysian Industries. Journal of Intellectual Capital, v. 1 , i. 1 , p. $85-100,2000$.

CABRITA, M. R.; BONTIS, N. Intellectual capital and business performance in the Portuguese banking industry. Int. J. Technology Management, v. 43, i. 1-3, 2008.

CADDY, I. Issues concerning intellectual capital metrics and measurement of intellectual capital. Singapore Management Review, v. 24, i. 3, p. 77-88, 2002.

CARVALHO, F. M.; KAYO, E. K.; MARTIN, D. M. L. Tangibilidade e intangibilidade na determinação do desempenho persistente de firmas brasileiras. Revista de Administração Contemporânea, Curitiba, v. 14, n. 5, p. 871-889, set./out. 2010.

CENDÓN, B. V. Bases de dados de informação para negócios. Ciência da Informação, v. 31, n. 2, p. 30-43, 2002.

CHEN, M. C.; CHENG, S. J.; HWANG, Y. An empirical investigation of the relationship between intellectual capital and firms' market value and financial performance. Journal of Intellectual Capital, v. 6, i. 2, p. 159-176, 2005.

COHEN, S.; KAIMENAKIS, N. Intellectual capital and corporate performance in knowledge-intensive SMEs. The Learning Organization, v. 14, i. 3, p. 241-262, 2007.

COLAUTO, R. D. et al. Evidenciação de ativos intangíveis não adquiridos nos relatórios da administração das companhias listadas nos níveis de governança corporativa da Bovespa. Revista Contabilidade Vista \& Revista, v. 20, n. 1, p. 142-169, 2009.

COMITÊ DE PRONUNCIAMENTOS CONTÁBEIS (CPC). Pronunciamento Técnico CPC 04 - Ativos Intangíveis. Disponível em: $<$ http://www.cpc.org.br>. Acesso em: 23 out. 2012.

COUTO, P. B. Ativos intangíveis e o desempenho econômico das empresas do novo mercado. 2009. Dissertação (Mestrado em Ciências Contábeis)-Centro de Pós-Graduação e Pesquisas em Contabilidade e Controladoria (Cepcon) da Faculdade de Ciências Econômicas da Universidade Federal de Minas Gerais, Belo Horizonte, 2009. 
DASKE, H.; GEBHARDT, G. International financial reporting standards and experts' perceptions of disclosure quality. ABACUS, v. 42, i. 3/4, p. 461-498, 2006.

DENICOLAI, S.; ZUCCHELLA, A.; STRANGE, R. Knowledge assets and firm international performance. International Business Review, i. 23, p. 55-62, 2014.

DOIDGE, C.; KAROLYI, G. A.; STULZ, R. M. Why do countries matter so much for corporate governance? Journal of Financial Economics, i. 86, p. 1-39, 2007.

EDVINSSON, L.; MALONE, M. S. Capital Intelectual: descobrindo o valor real de sua empresa pela identificação de seus valores internos. São Paulo: Makron Books, 1998.

ENSSLIN, S. R. et al. Grau de intangibilidade e retorno sobre investimentos: um estudo entre as 60 maiores empresas do índice Bovespa. Ciências Sociais em Perspectiva, v. 8, p. 101-118, 2009.

FÁVERO, L. P. et al. Análise de dados: modelagem multivariada para tomada de decisões. Rio de Janeiro: Elsevier, 2009.

FIRER, S.; WILLIAMS, S. M. Intellectual capital and traditional measures of corporate performance. Journal of Intellectual Capital, v. 4, i. 3, p. 348-360, 2003.

GOLDFINGER, C. Intangible Economy and its Implications for Statistics and Statisticians. International Statistical Review, v. 65, i. 2, p. 191-220, 1997.

HAIR JÚNIOR, J. F. et al. Análise multivariada de dados. 6. ed. Porto Alegre: Bookman, 2009.

HITT, M. A.; IRELAND, R. D.; HOSKISSON, R. E. Administração

Estratégica: Competitividade e Globalização. 4. ed. São Paulo: Thomson, 2003.

HUYGHEBAERT, N.; LUYPAERT, M. Antecedents of growth through mergers and acquisitions: Empirical results from Belgium. Journal of Business Research, v. 63, p. 392-403, 2010.

IAS 38 - Ativos Intangíveis. In: Normas internacionais de relatório financeiro (IFRS): conforme emitidas até $1^{\circ}$ de janeiro de 2009. São Paulo: IBRACON Instituto dos Auditores Independentes do Brasil, p. 1697-1726, 2010.

KANG, H. H.; GRAY, S. J. Reporting intangible assets: voluntary disclosure practices of top emerging market companies. International Business Review, v. 23, p. 55-62, 2014. 
KAYO, E. K. A estrutura de capital e o risco das empresas tangível e intangível intensivas. 2002. Tese (Doutorado em Administração)-Departamento de Administração da Faculdade de Economia, Administração e Contabilidade da Universidade de São Paulo, São Paulo, 2002.

KLANN, R. C. Gerenciamento de resultados: análise comparativa de empresas brasileiras e inglesas antes e após a adoção das IFRS. 2011. Tese (Doutorado)Universidade Regional de Blumenau, Blumenau, 2011.

LEV, B. Intangibles: management, measurement and reporting. Washington: Brookings, 2001.

MARTINS, E. Contribuição à avaliação do ativo intangível. 1972. Tese (Doutorado em Contabilidade)-Universidade de São Paulo, São Paulo, 1972.

MURTHY, V.; MOURITSEN, J. The performance of intellectual capital: mobilizing relationships between intellectual and financial capital in a bank. Accounting, Auditing \& Accountability Journal, v. 24, i. 5, p. 622-646, 2011.

NASCIMENTO, E. M. et al. Ativos intangíveis: análise do impacto do grau de intangibilidade nos indicadores de desempenho empresarial. Reflexão Contábil, Maringá, v. 31, n. 1, p. 37-52, jan./abr. 2012.

OREIRO, J. L. A crise na Europa e os dilemas da Espanha. Desdobramentos da crise financeira internacional. Revista de Economia Política, v. 31, n. 2, p. 315$335,2011$.

PARK, J. C. et al. Business in troubled waters: does adverse attitude affect firm value? Journal of Corporate Finance, i. 22, p. 221-235, 2013.

PAULA; L. F.; FERRARI FILHO, F. Tempos Keynesianos. Desdobramentos da crise financeira internacional. Revista de Economia Política, v. 31, n. 2, p. 315-335, 2011.

PEREZ, M. M.; FAMÁ, R. Ativos intangíveis e o desempenho empresarial. Revista Contabilidade e Finanças, São Paulo: USP, n. 40, p. 7-24, jan./abr. 2006.

SÁENZ, J. Human capital indicators, business performance and market-to-book ratio. Journal of Intellectual Capital, v. 6, i. 3, 2005.

SRIRAM, R. S. Relevance of intangible assets to evaluate financial health. Journal of Intellectual Capital, v. 9, i. 3, p. 351-366, 2008. 
STEWART, T. A. Capital intelectual: A nova vantagem competitiva das empresas. Rio de Janeiro: Campus, 1998.

SVEIBY, K. E. A Nova Riqueza das Organizações: Gerenciando e Avaliando Patrimônios de Conhecimento. Rio de Janeiro: Campus, 1998.

TAN, H. P.; PLOWMAN, D.; HANCOCK, P. Intellectual capital and financial returns of companies. Journal of Intellectual Capital, v. 8, i. 1, p. 76-95, 2007.

TOVSTIGA, G.; TULUGUROVA, E. Intellectual capital practices and performance in Russian enterprises. Journal of Intellectual Capital, v. 8, i. 4, p. 695-707, 2007.

TOVSTIGA, G.; TULUGUROVA, E. Intellectual capital practices: a four-region comparative study. Journal of Intellectual Capital, v. 10, i. 1, p. 70-80, 2009.

WANG, W. Y.; CHANG, C. Intellectual capital and performance in causal models: Evidence from the information technology industry in Taiwan. Journal of Intellectual Capital, v. 6, i. 2, p. 222-236, 2005.

\section{COMO CITAR ESTE ARTIGO:}

DALLABONA, Lara Fabiana; MAZZIONI, Sady; KLANN, Roberto Carlos. A influência do grau de intangibilidade no desempenho de empresas sediadas nos países com turbulência econômica. RACE, Revista de Administração, Contabilidade e Economia, Joaçaba: Ed. Unoesc, v. 14, n. 3, p. 1035-1062, set./ dez. 2015. Disponível em: < http://editora.unoesc.edu.br/index.php/race>. Acesso em: dia/mês/ano.

Dallabona, L. F., Mazzioni, S., \& Klann, R. C. (2015). A influência do grau de intangibilidade no desempenho de empresas sediadas nos países com turbulência econômica. RACE, Revista de Administração, Contabilidade e Economia, 14 (3), 10351062. Recuperado em dia/mês/ano, de http://editora.unoesc.edu.br/index.php/race 
